\title{
„TROR DE, GUD ER DØV?”
}

\author{
Lyden af bøn som social kritik i det sydlige Ghana
}

\section{KASPER JELSBECH KNUDSEN}

En fredag formiddag i oktober 2014 sad jeg i receptionen i Harvest Chapel International (HCI), kirken i Accra, hvor jeg gennem ti måneder udførte etnografisk feltarbejde. Jeg skulle mødes med en af kirkens såkaldte spiritual warriors, Eric, som netop var i færd med at afslutte et bønnemøde i kirkeauditoriet. Fra auditoriet kunne man høre en forvrænget lyd af Erics stemme, der i en blanding af tungetale og engelske fraser råbte i mikrofonen, at de ville bekæmpe satan med bøn og „bryde de dæmoniske lænker“, som lagde sig som en forbandelse over ikke blot medlemmerne af HCI, men hele Ghana og afholdt dem fra at opnå rigdom og velvære. Deltagerne, hvis bedende stemmer summede i baggrunden af Erics stemme, var der for at deltage i det ugentlige Solution Center, som HCI afholder hver fredag, hvor folk kommer for at bede for at finde løsninger på udfordringer i deres liv.

Mens jeg lyttede til deres bøn fra auditoriet, bemærkede jeg en ung mand, som sad lidt væk og kiggede på mig. Efter lidt tid rejste han sig og gik hen og satte sig hen ved siden af mig. Han præsenterede sig som Kwame. „Har du nogensinde tænkt over, hvorfor vi ghanesere beder så meget?“ spurgte Kwame mig. Det havde jeg, svarede jeg. Kwame uddybede: „Vi beder, fordi livet her i Ghana er hårdt. Som kristne tror vi på, at vi skal kunne se frugterne af vores tro. Det er budskabet, hvis du lytter til prædikanter som Eastwood Anaba og Joel Osteen. ${ }^{1}$ Troen skal vise sig i konkrete resultater her på jorden, som kan skabe en forandring. Men vi ser ikke de resultater i vores eget liv.“ Jeg spurgte Kwame, hvad der efter hans mening gjorde, at resultaterne udeblev. Kwame var hurtig til at svare: „Vi tager os ikke tid til at lytte efter et svar. Hvis jeg spørger dig om noget og derefter går væk uden at høre, hvad du siger, så får jeg jo ikke det svar, jeg søger. Prøv at høre dem derinde [fra auditoriet]. De råber og skriger konstant. Tror de, Gud er døv? Tro handler ikke om, hvor højt du kan bede, men om du har disciplinen til at lytte efter Helligåndens svar og adlyde Ham.“ 


\section{Bøn som social kritik}

I denne artikel tager jeg udgangspunkt i Kwames kritik af sine kristne trosfællers måde at praktisere bøn på. Kwames kritik resonerede nemlig med flere kritiske stemmer i kirken, der centrerede sig om problemet med de „udeblevne resultater“ på grund af manglende spirituel orden og disciplin. Som en af lederne i HCI, Ray, sagde til mig efter en søndagsgudstjeneste, er der for mange medlemmer, der ønsker ,hurtige fix“", hvor de kommer til et bønnemøde og råber og skriger, falder om på gulvet og derefter vender tilbage til deres normale liv uden at studere Biblen, faste, bede og lytte efter Helligånden. Denne kritik var stigende i løbet af mit etnografiske feltarbejde i HCI og andre lignende kirker. Mit feltarbejde, som strakte sig over ti måneder i 2013-2015, faldt sammen med en periode i HCI, hvor kirkens ledere udviklede ambitiøse visioner om at ekspandere kirken og dens medlemstal dog uden at kunne se disse resultater plante sig. Samtidig var det en periode, hvor visse medlemmer af HCI, som jeg boede hos som en del af mit deltagerobserverende feltarbejde, oplevede store udfordringer med at få dækket behovene i dagligdagen uden for kirken. Det fik både lederne og flere af mine informanter til at understrege for mig, at disciplin og orden - både i forhold til bønspraksisser og i forhold til andre aspekter af livet som troende - var nødvendigt, for at troen kunne få en effekt i deres liv og ikke mindst for kirkens udbredelse. Men for dem var denne disciplin og orden bemærkelsesværdigt fraværende, og som jeg vil vise senere i artiklen, var denne empiriske problemstilling mellem det ordnede og disciplinære på den ene side og det uordnede og udisciplinerede på den anden side ikke blot et problem i HCI, men også en bredere social kritik af, hvad flere karismatiske kristne oplevede som et større samfundsproblem.

Hovedargumentet for denne artikel er, at lyden af bøn som social og religiøs praksis udtrykker den empiriske problemstilling mellem det ordnede og uordnede, mellem vedholden disciplin og kortvarig forløsning for mine informanter i HCI. Kernen i argumentet og den empiriske problemstilling, som jeg fremstiller her, er ikke så meget, at de karismatiske kristne tidligere dyrkede det spontane og ukontrollerbare og nu går i den modsatte retning mod kontrol og disciplin. Argumentet er snarere, at det karismatiske trosfællesskab i HCI, som er centreret omkring bøn, tager sig ud som en bevægelse mellem disse to kontraster. Bønnen bliver så at sige den måde, hvorpå de kristne på den ene side forsøger at dyrke et disciplineret kristent selv, som efterfølgende kan påvirke samfundet, og på den anden side den praksis, hvormed de forholder sig kritisk til de selv samme negative tendenser hos sig selv og samfundet, som skaber behovet for sociale grænsedragninger og territoriel kontrol i en by, hvor kampen for tilhørsforhold tager sig ud fysisk såvel som spirituelt for såvel de karismatiske kristne som for andre religiøse grupper. 
Tidligere antropologiske studier af karismatiske pinsekristne ${ }^{2}$ har fokuseret på de kristnes italesættelse af radikale brud med tidligere identiteter eller andre religiøse retninger. Karismatiske kristne fremstår således som manifesteringen af en særlig form for kristendom, der kapper bånd til lokale steder og andre religiøse identiteter til fordel for en mere grænseløs, globaliseret tro (Meyer 1998, 1999; van Dijk 2001a; Robbins 2004a, 2004b, 2006). Uden at negligere betydningen af den grænseløse tro for karismatiske fællesskaber argumenterer jeg dog for, at de karismatiske kristne i HCI selv er blevet kritiske overfor den måde, hvorpå deres tro praktiseres. For dem er den spontane praktisering af troen gennem højlydt bøn blevet et problem, en kilde til kritisk selvrefleksion og et opgør i deres trosfællesskab.

Det er med andre ord vigtigt at undersøge bøn. For det første, fordi bøn er den praksis, som de kristne ghanesere, jeg arbejdede med, bruger mest på tid på og generelt er mest optaget af som et våben til at bekæmpe negative åndelige magter. Bønnen, argumenterer jeg, antager både en centripetal kraft, som er indadrettet mod den personlige dyrkelse af mere disciplinerede, kristne subjekter, og en centrifugal kraft, som er udadrettet mod en social forandring af samfundet. For det andet, fordi bøn samtidig bliver selve genstanden for kritik og dermed et middel til at redefinere betydningen af den kristne tro i forhold til sig selv og menigheden i konteksten af de samfundstendenser, der skaber rammerne for kirkens og dermed troens udfoldelse. I det følgende afsnit vil jeg første beskrive, hvordan de ovennævnte centripetale og centrifugale kræfter tager sig ud etnografisk. Vi begynder i hjemmet hos to unge medlemmer af HCI, Isaac og Doreen, som jeg boede hos i syv måneder i løbet af mit feltarbejde. Dernæst inddrager jeg en social kritik, som blev givet af en af Ghanas mest indflydelsesrige karismatiske prædikanter til en kristen konference.

\section{Bønnens centripetale kraft}

Hver morgen, før solen stod op, før morgentrafikken kunne høres ude foran, og mens det bølgende lydtæppe af frøer og cikader stadig hang tungt i luften, blev jeg vækket af enten Isaac eller Doreen, der uden at sige noget til mig åbnede døren ind til mit værelse. Det var et tegn til, at jeg skulle stå op og deltage i morgenbønnen. Morgenbønnen havde sin faste struktur, som var direkte overført fra praksis i deres kirke, HCI. Afhængigt af nattens forløb var bønnen mere eller mindre energisk. Særligt efter varme nætter uden elektricitet var vi alle tre lidt længere tid om at komme i gang. Efter at være kravlet ud under myggenettet, som hang over min madras på gulvet, sluttede jeg mig til Isaac og Doreen, og vi gik alle tre rundt imellem hinanden lettere søvndrukne og med nattens støv klistret 
til huden, mens vi sang salmer på twi $i^{3}$ og gik gennem rummene i det hus, vi for en stund havde lejet. Efter salmerne samledes vi, og en af os - som regel Isaac - ville foreslå et tema for vores bøn. Temaer kunne være en nærtforestående rejse med kirken, en eksamen, vores familiers helbred eller Ghanas økonomiske og politiske fremgang. Herefter fulgte 20-30 minutters bøn i stigende intensitet, hvor jeg sammen med Isaac og Doreen skiftende mellem engelsk og tungetale ville erklære, at Gud ville gøre alting godt gennem Helligåndens tilstedeværelse, og at Satan og hans dæmoner forblev bandlyst. Bønnen afsluttedes altid med, at vi sad i deres sofa og læste højt fra Biblen - et slags dagens vers, som vi brugte til at tale om lokale og globale begivenheder, som prægede vores liv i Ghana og Danmark. Efter morgenbøn gjorde Isaac sig klar til at tage på arbejde i HCI, hvor han arbejdede som chauffør, mens Doreen og jeg så koreanske sæbeoperaer, hvilket var Doreens favoritfritidsbeskæftigelse, inden vi også gjorde os klar til at tage af sted.

Efter bøn en morgen i 2014, mens Doreen tændte for tv'et, fik jeg øje på et billede af Mensa Otabil, en af de mest anerkendte karismatiske prædikanter i Ghana, med et engelsk citat nedenunder: „Dæmoniske stemmer imiterer ofte Helligåndens stemme“ (min oversættelse). Jeg pegede på skiltet og spurgte Doreen, hvad hun troede, at det betød. „A-haa,“ sagde hun og nikkede genkendende med et smil. „Vi hører altid to stemmer. Helligånden forsøger at fortælle dig, hvad du skal gøre, men alt for ofte bliver Han overdøvet af Satan, som taler endnu højere. Alt for ofte lader vi os påvirke af den højeste stemme. Bare se på politikerne i Ghana. De tænker kun på deres mave og på at fifle med regnskaberne ved at stjæle lidt hist og her (uwia nkete nkete). Hvis ikke vi sørger for at bede hver dag og læse Biblen, vil Satans stemme overdøve Helligånden. Vi er nødt til at bruge bønnen til at bekæmpe Satan." For både Doreen og Isaac var der beviser for denne type moralsk og åndelig korruption overalt i Ghana. Fra nyheder om nepotisme i regeringen og økonomisk bedrageri i politiske partier og nationale virksomheder til mere dagligdagsproblematikker såsom manglende elektricitet, stigende priser på benzin og mad og manglende boliger og plads i storbyen, som syntes at vokse ukontrollerbart for hver dag. Men de var også selv modtagelige for at lytte til den forkerte stemme. På dage, hvor vi sov over os, eller hvis Isaac og Doreen havde haft et skænderi, var det for dem et udtryk for, at de ikke havde lyttet til Helligånden, hvilket i sidste ende ville medføre, at de guddommelige ,frugter" af deres tro ville udeblive. For dem var det især et fast sted at bo, der ville udeblive. I de syv måneder, jeg boede sammen med Isaac og Doreen, flyttede vi fire gange, og hverdagen var ofte præget af usikkerhed om, hvorvidt udlejeren ville opsige lejemålet. Hver gang vi flyttede, fik vi at vide, at vi kun kunne være der midlertidigt, og at vi snart skulle flytte ud. Dertil kom, 
at Isaac arbejdede i HCI seks og nogle gange syv dage om ugen fra morgen til sen aften, hvilket kun gjorde deres situation endnu mere udmattende. Derfor krævede det en særlig form for „disciplin“ og „underkastelse“, fortalte Doreen mig, at komme op tidligt hver morgen for at bede, når kroppen hellere vil sove efter at være kommet hjem sent om aftenen fra gudstjeneste i kirken eller lange ture rundt $\mathrm{i}$ landet for at missionere.

I rammerne af deres private hjem var troen derfor hårdt arbejde, der krævede kontinuerlige handlinger, hvis formål var at kultivere ikke blot et spirituelt selv, men et etisk selv på samme måde, som Ruth Marshall beskriver i sit studie af born again-kristne i Nigeria. Her belyser Marshall såkaldte „troshandlinger“ (acts of faith) som en måde, hvorpå de kristne underkaster sig en større magt, der ligger uden for individet (Marshall 2009:145). Troshandlinger kan her ses ikke kun som bøn eller bibelstudie, men alle aktiviteter, der associeres med deres kristne tilværelse såsom at betale tiende hver måned til kirken, at påtage sig ekstra opgaver i kirken eller at faste. For Isaac og Doreen var troshandlinger alle aktiviteter, som havde til formål at opbygge disciplin gennem underkastelse for derved bedre at kunne høre Helligåndens stemme. Dog var bønnen den mest centrale troshandling. Ofte fortalte Doreen og Isaac mig på samme måde som Kwame, at folk gik i kirke blot for at blive set og bede højlydt, men ikke lytte til et svar, hvorfor frugterne af deres tro ville udeblive. For dem var materiel stagnering derfor et umiddelbart tegn på, at ens tro ikke var stærk nok, fordi man som kristen ikke lyttede til Helligånden, og dermed et udtryk for manglende disciplin forårsaget af ens synder. Som en særlig vigtig troshandling antager bønnen på den måde en centripetal kraft, som har til formål at kultivere et disciplineret kristent subjekt. For Doreen og Isaac var det et spørgsmål om altid at være på vagt over for deres egen utilstrækkelighed, der gjorde dem sårbare for åndelige angreb ved at lytte til den forkerte stemme. På samme måde måtte de derfor også være parate til at opfange de ord, som Helligånden i løbet af en dag kunne sige til dem. Den pointe blev gentaget af selv samme Mensa Otabil til en karismatisk konference i 2013 med temaet „Guddommelige ord“, hvor jeg deltog. Her understregede han særligt den centrifugale kraft ved kristen disciplinering, som et udadrettet potentiale til at skabe sociale forandringer i Ghana.

\section{Bønnens centrifugale kraft}

Til konferencen var Otabil hovedtaleren, og hans oplæg centrerede sig om skabelsesberetningen i 1. Mosebog for at pointere, at Guds orden i verden ikke var afspejlet i Accra. Udover at være et forbillede for mange af medlemmerne af HCI var og er Otabil også en af de mest indflydelsesrige prædikanter i Ghana, der 
kritiserer den måde, som det urbane samfund har præget de karismatiske trosfællesskaber negativt på. Otabils stil som prædikant er i den henseende interessant at bemærke, fordi stilen afspejler hans budskab. Modsat den gængse karismatiske prædikant i de fleste kirker råber Otabil aldrig. Han taler afdæmpet, holder mange og til tider lange pauser. Han beder tilhørerne om ikke at afbryde ham med tilråb som „,preach“, ,amen“ osv., hvilket ellers er normen. Hans prædikener begynder altid til tiden og slutter til tiden, og der er ingen plads til spontanitet og uventede drejninger. Når Otabil taler, forekommer han i fuld kontrol, ikke blot over sit budskab, men over salen. Og netop budskabet med kontrol, orden og disciplin eller mangel på samme var Otabils pointe den aften, hvor han brugte skabelsesberetningen som fortolkningsramme til at beskrive den overbefolkede, urbane udvikling, som ifølge Otabil karakteriserede Ghanas byer. Jeg citerer her Otabil:

Årsagen til, at vi har så mange problemer i Ghana, er en simpel mangel på orden. Ligesom Gud bragte lys til verden for at skabe orden, har vi i Ghana brug for klarhed udefra. Vores problemer er ikke økonomiske, og vi mangler ikke ressourcer. Vores problem er manglende orden, fordi kaos er blevet vores nye normale. I en kaotisk situation kan enhver person sætte en butik op, hvor han vil. Der er ingen tomme parker i Ghana. Vi har bygget overalt. På hvert fortov, i hver baghave, på hver tomme plads sætter vi et eller andet op. Da Gud skabte jorden, adskilte Han land fra hav. Når vandet bryder dets grænser og flyder ind over landjorden, skaber det oversvømmelse og kaos. Vandet skal flyde adskilt fra jorden. I er som vand. Gud har skabt et sted for jer. Flyd dér!

Otabils analogi fra skabelsesberetningen med vandet, der brød dets grænser og skabte oversvømmelse, som fortolkning af den urbane udvikling i Ghana og særligt Accra var rammende i lyset af en tiltagende offentlig opmærksomhed på Accras befolkningstilvækst, som også påvirkede kirkerne. Tilvæksten skabte i stigende grad konflikter over rettigheder til jord og land, idet adskillige parter ofte kunne dokumentere eller kræve brugsretten til et stykke jord i byen, hvorfor mange konflikter over brugsret ofte endte med, at hvem der end besatte et område, fik lov at være der. Overbefolkningen i Accra og den manglende kontrol med jordbrugsret blev i medierne jævnligt forbundet med moralske problemstillinger, der tilsammen syntes at give en fornemmelse af, at Ghana var oversvømmet med problemer og kaos, som Otabil prædikede (se figur 1). 


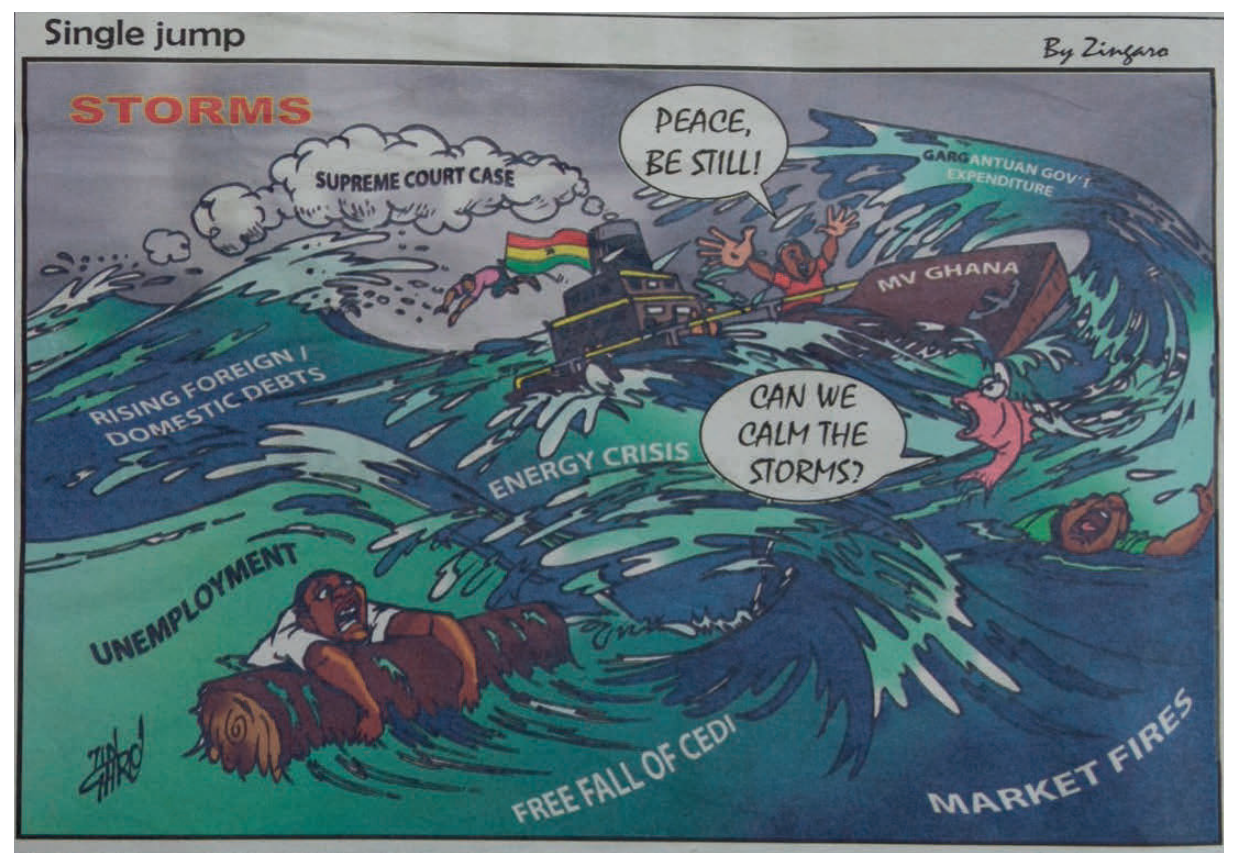

Figur 1. Grafisk illustration i ghanesisk avis. Kilde: Daily Graphic, 16.6.2013.

Det er i konteksten af Otabils prædiken, at jeg argumenterer, at vi skal forstå Kwames kritik af den højlydte bøn i HCI-auditoriet, som ikke blot en teologisk kritik, men også en bredere social kritik. Den overdøvende lyd fra HCI-auditoriet og mange andre karismatiske kirker bliver i sig selv et tegn på det ukontrollerede, det udisciplinerede, det, som emblematisk signalerer det urbane samfunds og trosfælleskabets mangel på grænser og orden.

\section{Hellige lyde i Accra og religiøs modernitet}

I dag er det svært ikke at bemærke, hvordan lyden af prædikener, sange og bøn fra karismatiske kirker i Accra præger bybilledet. Det virkede ofte for mig, som om de forskellige kirker og trosfællesskaber forsøgte at overdøve hinanden i en kakofoni, der med Marleen de Wittes begreb kan beskrives som en ,sonisk helliggørelse" (sonic sacralization) af det urbane miljø (de Witte 2008). Det er en sonisk helliggørelse, som med jævnlige all night prayers ${ }^{4}$ aldrig synes at stilne hen. Og netop den til alle tider nærværende støj af skrattende højtalere, der projicerer profetiske budskaber fra energiske prædikanter i bøn akkompagneret af perkussioninstrumenter og trommesæt, forstærkede klaverer, guitarer og elbasser, skaber jævnligt kontroverser i Accra og i særdeleshed imellem forskellige kristne 
grupper. For de såkaldte ,traditionelle“ grupper i Ghana, som er tilknyttet de europæiske missionskirker og dermed ikke er karismatiske, er støj fra kirker som HCI et problem særligt én gang om året.

I sommermånederne fejrer forskellige etniske grupper den årlige høst, hvilket er en gammel praksis, der går forud for kristendommens udbredelse i Ghana og stadigvæk associeres med forskellige etniske gruppers oprindelse og de hertil beslægtede forfædreånder. Af samme årsag tager de fleste karismatiske kirker afstand fra denne årlige fejring, som de betegner som djævelsk forfædredyrkelse. Forud for den traditionelle fejring af høsten er der i en måned pålagt et rituelt forbud mod musikalsk støj. Det har tidligere ført til fysiske sammenstød mellem de karismatiske kristne og de traditionelle grupper over netop problemet med støj (Van Dijk 2001b; de Witte 2008). Ifølge de traditionelle grupper forstyrrer larmen forfædreånderne, som skal sikre en god høst, hvorfor der i århundreder har været et forbud mod støj i måneden før høsten (typisk omkring maj). Som beskrevet af Birgit Meyer (1999) anses forfædreånderne for dæmoniske af Ghanas karismatiske kirker, og derfor er kampen om den soniske helliggørelse ikke blot et spørgsmål om fysisk tilstedeværelse, men i lige så høj grad et spørgsmål om en åndelig kamp for territoriel besættelse. De karismatiske kirker skal med andre ord larme for at holde forfædrenes ånder væk.

Historisk anvendtes lyd og musik i rituelle begivenheder blandt Ghanas oprindelige høvdingedømmer til at skabe en barriere (pampin), der skulle sikre åndelig beskyttelse inden for lydens rækkevidde, således at forfædreånderne i fred og ro kunne sikre god høst uden indblanding fra andre, ondsindede ånder (Kaminski 2014). På samme måde kan musikken siges at skabe en spirituel barriere i de karismatiske kirker, men her står kampen mellem Gud og de dæmoniske og hedenske ånders tilstedeværelse. Lyd er altså et helt centralt fænomen blandt Accras kirker og religiøse fællesskaber. Ikke blot er lyd en måde, hvorpå forskellige grupper så at sige erobrer det spirituelle rum, men det bliver også en måde, hvorpå de etablerer deres religiøse identitet i offentlige rum. For at belyse sammenhængen mellem lyd og territoriel grænsedragning er det relevant at inddrage den franske sociologi Danielle Hervieu-Légers begreb om religiøs modernitet (2002).

Kendetegnet for religiøs modernitet er ifølge Hervieu-Léger et brud mellem tro og territorielt tilhørsforhold; et bånd, som kirkerne historisk set har haft monopol på i vestlige samfund (Weber 1991). Den religiøse modernitet, hævder HervieuLéger ydermere, er en følgevirkning af særligt fem karakteristika i den globaliserede tidsalder: 1) Et stigende antal kirker kæmper for at hverve og beholde medlemmer. 2) Tro individualiseres og tilpasses specifikke kontekster. 3) Afviklingen af traditionelle bånd til lokale steder og fortiden. 4) Øget global migration. 5) Nye teknologiske muligheder for kommunikation (Hervieu-Léger 2002). Som et ek- 
sempel på religiøs modernisering har Matijn Oosterbaan dokumenteret i sit studie af karismatiske kristne i en af Rios favelaer, hvordan de kristne trækker territorielle grænser ved at afspille høj gospelmusik for at overdøve andre musikgenre fra ikkekristne grupper. Oosterbaan kalder dette fænomen for ,sonisk overlegenhed“ (sonic supremacy) (Oosterbaan 2009). Oosterbaans argument er, at den allestedsnærværende støj af musik i favelaen er udtryk for forskellige ideologiske ståsteder, som dermed trækker territorielle grænser for folks tilhørsforhold til den ene eller anden ideologiske gruppe (op.cit.97). Oosterbaan tager således sit analytiske udgangspunkt i Hervieu-Légers teoretiske fremstilling af den religiøse modernitet og herunder medieringen af tro og tilhørsforhold gennem elektronisk kommunikation.

Den materielle mediering af tro og tilhørsforhold finder Andreas Bandak på lignende vis blandt syriske muslimer og kristne i Damaskus. Her bruger både kristne og muslimer visuelle dekorationer og lyd til at trække grænser i det sociale rum. Bandak argumenterer, at disse visuelle og soniske markører fungerer som ,refræner" (jf. Deleuze \& Guattari 2015), der indskriver materielle narrativer i det urbane landskab (Bandak 2014:254). Den materielt medierede grænsedragning gennem lyd og visuelle refræner er ingenlunde nedtonet i konteksten af Accras urbane landskab. Her er store og ofte farverige skilte en konstant påmindelse om kristne og særligt karismatiske narrativer om synd og genfødsel akkompagneret af skrattende højtalere, tamburiner og trommer, der understøtter store og små menigheder i bøn fra Accras utallige formelle og uformelle kirker (se figur 2).

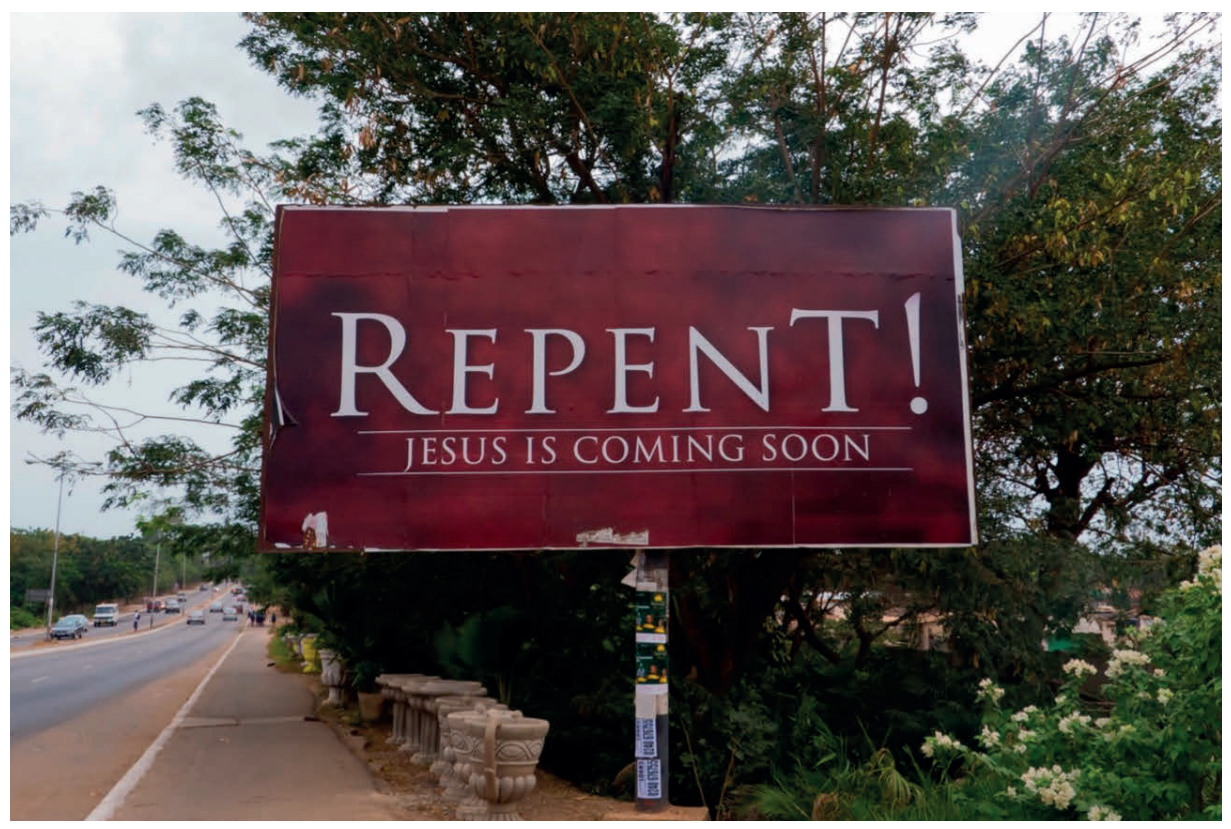

Figur 2. Billboard i Accra. Foto: Kasper Jelsbech Knudsen. 
Foruden de store skilte kan lyden af bøn og musik ses som en form for kristne refræner i Accra; en slags metonymisk repræsentation af de karismatiske fællesskabers historiske og politiske tilstedeværelse og opgør med missionskirkerne i det urbane landskab. På samme måde som kristne i Rios favelaer bruger musik som grænsedragning, kan vi ligeledes anskue den højlydte, karismatiske bøn som en form for sonisk overlegenhed, hvis formål det er at gøre krav på såvel socialt som åndeligt rum. Udfordringen for de karismatiske kristne er dog, at så snart hundredvis af kirker i tætbefolkede områder forsøger at etablere sonisk overlegenhed, forsvinder de hver især i larmen. Det er ikke længere muligt at adskille den enkelte kirke fra andre, fordi de soniske grænser bliver flydende og uklare. Midt i denne støjende kakofoni bliver det svært at lytte efter Helligånden, som Doreen sagde. På den måde bliver lyden i sig selv problematisk, fordi forskellige gruppers lyduniverser let sammenblandes, hvilket i ghanesisk ontologisk forstand skaber mulighed for dæmonisk indblanding. Men eftersom Helligånden som oftest menes at kommunikere gennem andre mennesker i bøn, er de personer, som kan kanalisere guddommelige budskaber gennem bøn, nødt til at råbe endnu højere, for at menigheden kan høre dem. At fange Helligåndens ord gennem såkaldt profetisk tale kræver nemlig ifølge Eric, som jeg præsenterede i indledningen, at man som tilhører kan skelne mellem bønnens tre faser. I det følgende afsnit vil jeg inddrage Erics syn på bøn, som han i kraft af sin titel som spirituel kriger praktiserer det i HCI.

\section{Bøn og spirituel krigsførelse}

Eric er en høj og fysisk stærk ung mand, udadvendt og med en udstråling, der synes at gøre ham særlig attraktiv blandt mange af kirkens unge kvinder. Og så er Eric spirituel kriger. En spirituel kriger (spiritual warrior) er en person, som ved sin kristne genfødse ${ }^{5}$ og medlemskab af kirken melder sig til at være ansvarlig for at forsvare kirken og kirkens ledende pastorer imod spirituelle angreb. Det gør de spirituelle krigere såsom Eric ved at bruge det meste af deres tid på bøn. For Eric skal titlen som ,kriger" forstås bogstaveligt. Han havde selv oplevet, hvordan et dæmonisk angreb næsten kostede ham livet en aften, hvor han og andre unge fra HCI var ude for at missionere. Mens Mel Gibson's The Passion of the Christ spillede på storskærm og oplyste den mørke aften i et landligt område uden for Accra, blev Eric pludselig ramt af voldsom diarre og faldt efterfølgende om og måtte køres på hospitalet. Det viste sig efterfølgende, at han var ramt af kolera og måtte tilbringe en uge på intensivafdeling $\mathrm{i}$ isolation. For Eric var selve diagnosen ikke så vigtigt. Det var snarere det, at han blev ramt, imens han var i færd med af ,affolke helvede“, som han udtrykte det til mig. At han blev ramt i netop den 
situation, betød for Eric, at der var tale om et dæmonisk angreb. Et angreb, der rammer særligt spirituelle krigere, hvis de ikke er forberedt på det.

På grund af denne oplevelse tog Eric det derfor på sig at bruge så meget af sin tid som muligt på bøn - herunder også at skole mig i at bede for at modstå spirituelle angreb. Som en del af min træning med Eric forklarede han mig en eftermiddag, hvordan bønnen bygger sig op hen over tre faser. „Den første fase,“ sagde Eric, ,er, når du begynder bønnen. Måske er du lige kommet fra arbejde eller lige stået op af sengen, og du tænker på alt muligt andet.“ I kirken kendetegnes denne fase ofte ved en relativt lav intensitet, hvor folk lidt efter lidt ankommer til kirkesalen og går rundt blandt hinanden og beder på engelsk. Nogle kigger på deres telefoner og synes, som Eric siger, ofte at være distraheret af andre emner. „Fase 2,“ fortsatte Eric, ,er, hvor du bliver fokuseret på Gud, men dæmonerne står i vejen for dig, og du er nødt til at overkomme dem. " Med tiden lærte at jeg at genkende tegnene på det, som Eric kalder fase $2 \mathrm{i}$ bønnen. Det opstod, når bønnen i kirken eller hjemme hos Isaac og Doreen blev mere intens. Ofte kunne jeg høre dem blande engelske fraser med tungetale. Det kunne fx lyde således: „Oh, Lord let no demon come my way. Mandolobosi abranda kapalusa. Thank you Jesus. Okapaya pantela bosi.“

„Endelig hvis du når fase 3,“ afsluttede Eric, ,er du i Guds tilstedeværelse. Det er her, hvor du kan plukke frugterne af din tro og se, hvad Han har til dig. Det er her, hvor vi kan tale profetiske ord. Så det gælder om at lytte efter, så du ikke misser det, der var beregnet til dig." Når Eric ledte bønnen i HCI, sad jeg ofte bag trommerne og spillede sammen med en pianist og en bassist dybe, underliggende toner og rytmiske fraser til at understøtte den mur af stemmer fra menigheden i bøn, der gik fra at være en samling individer til at være ét folk, som Thomas Csordas tidligere har beskrevet lyden og oplevelsen af den karismatiske bøn (Csordas 1997:109). Når intensiteten fra musikken og menigheden i bøn var på sit højeste, ville Erics stemme i mikrofonen skære igennem lydmuren med en hæs, næsten råbende stemme Raaaa ... Eeeeh ... Raaaa ... Med sine råbende enstavelsesord var Eric som regel i, hvad han selv karakteriserede som den tredje fase af bønnen. Her ville han fremmane profetiske erklæringer gennem Helligåndens tilstedeværelse. Faktisk, fortalte Eric mig, var det ikke længere Eric selv, men Helligånden, som talte. Men lyden af stemmer og musik nåede kun til et vist punkt. Ofte bemærkede jeg, hvordan folk bagerst i kirkesalen eller udenfor syntes af være afkoblet og distraheret af andre sager. Den spirituelle kraft rakte tilsyneladende kun så langt, at lyden stadig var det altoverdøvende. Dertil kom, at kraften også var tidsligt begrænset, fordi intensiteten fra lyden af musik og bøn varede ved i et bestemt tidsrum. Derfor handlede det om at være fokuseret både i og umiddelbart efter bønnen, hvor særlige profetiske ord (rhema-ord) kunne 
komme fra hvem som helst. En anden af de personer, som ofte oplevede at være et talerør for Helligånden, var Andy.

Andy er gospelsanger i HCI og optræder ofte umiddelbart efter Erics bøn. Ifølge Andy selv er han klar over, at de ord, han synger, ikke er hans egne, men kommer fra Helligånden, uden at Andy er klar over, hvem de er rettet mod. Derfor er det ifølge Andy op til folk at lytte nøje efter, så de ikke misser deres profetiske ord fra Helligånden. Af selv samme årsag er Andy meget påpasselig med verdslig musik, som han undgår at lytte til, fordi Djævlen bruger verdslige musikere som sit talerør. Ved at lytte til alt andet end gospel risikerer man derfor at blive påvirket af djævlen, som Doreen også fortalte mig.

\section{Kristen lyd i Accra og Abokobi}

Andys beskrivelse af vigtigheden af at lytte for at blive berørt af den guddommelige kraft er også blevet dokumenteret af Bruno Reinhardts studie af karismatiske pastorer under uddannelse i den karismatisk kirke, Lighthouse Chapel, i Accra. Som en del af deres træning tilbringer de kommende karismatiske pastorer adskillige timer dagligt med hver deres discman, hvor de lytter til indspilninger af prædikener af kirkens leder, Dag Heward-Mills. Ved at lytte til Heward-Mills' prædikener, en praksis, Reinhardt beskriver som soaking in tapes, bliver pastorerne gradvist i stand til at fange den guddommelige kraft medieret elektronisk gennem indspilningerne. Men det er samtidig en form for etisk praksis, argumenterer Reinhardt, hvorved pastorerne underkaster sig kirkens og lederens autoritet (Reinhardt 2014:328-29). Dette loyalitetsbånd har Karen Lauterbach i et andet studie af unge, ghanesiske pastorer beskrevet som et spirituelt fader-søn-forhold, og forholdet er et vigtigt element for de unge pastorers fremtidige succes som prædikanter (Lauterbach 2010).

På grund af den energiske og højlydte spirituelle praksis, som kendetegner de karismatiske kirker i Accra, hvorved Helligånden manifesterer sig gennem lyden af musik og bøn og dermed for en stund skaber et tilhørsforhold til et sted, har den antropologiske interesse i disse religiøse fællesskaber også centreret sig netop omkring medieringen af åndelig kraft gennem lyd og billede for derved at komme i berøring med den troende som i Reinhardts og Oosterbaans studier dokumenterer (men se også Meyer 2009, 2011; de Witte 2011; Hirschkind 2001). Men dette potentiale for mediering af åndelige kræfter gennem lyd og billede har også en negativ side, idet folk kan komme til at lytte til de forkerte ånder, hvilket ofte var kendetegnet for bymiljøet i Accra, som Doreen nævnte for mig. For meget støj gør, at Helligånden bliver overdøvet. Dette var blandt andet en af de vigtige årsager til, at lederne af HCI i oktober 2014 arrangerede en tur for de 
mandlige medlemmer af kirken til en lille by nord for Accra, Abokobi, hvor al offentlig støj var blevet forbudt.

Formålet med turen til Abokobi, som foregik hen over en weekend, var at blive inspireret af byens kristne styre. Abokobi er et religiøst og moralsk samfund isoleret fra Accras tilsyneladende korrumperende indflydelse. Abokobi er styret af et råd af ældre fra den presbyterianske kirke og er særlig kendt som en presbyteriansk by, der ikke tillader andre kirker eller trosfællesskaber at etablere sig i byen - heller ikke karismatiske kirker. Men eftersom der eksisterer religionsfrihed i Ghana, og der ikke må diskrimeres mod andre trosfællesskaber, har bystyret i Abokobi indført et forbud mod støj inklusive musik og sang alle dage og nætter undtagen søndag formiddag, hvor der er gudstjeneste i den presbyterianske kirke. For ydermere at afholde medlemmerne fra at deltage i karismatiske gudstjenester har den presbyterianske kirke i Abokobi også inkorporeret flere karismatiske elementer i søndagsgudstjeneste såsom musik og elektriske instrumenter og sporadisk tungetale. Forbuddet mod støj alle andre tidspunkter end søndag formiddag forhindrer i praksis andre kirker i at etablere sig i Abokobi, fordi de ikke kan gennemføre bøn eller gudstjeneste uden at larme. Da jeg spurgte en af HCI-arrangørerne om årsagen til, at en karismatisk kirke ville søge inspiration fra et presbyteriansk bystyre, som de historisk set netop havde brudt med, og særligt også i betragtning af, at man ikke må larme i Abokobi, svarede han, at det er, fordi Abokobi er „et sted kun for Kristus, og hvor de er seriøse i troen“. Abokobi, fortalte han mig, var inspirationen til HCI's planer om at etablere et hovedsæde i Shai Hills uden for Accra. Projektet, som gik under navnet Harvest City Project, var tænkt som et stort lukket område med hospital, skole, idrætsfaciliteter, beboelse og store auditorier til massegudstjeneste. Et sted kun for HCI.

\section{En bevægelse mellem tro og tilhørsforhold}

De etnografiske beskrivelser af bøn (eller måske snarere lyden af bøn), som jeg har præsenteret i denne artikel, synliggør et spændingsforhold mellem tro og tilhørsforhold blandt mine karismatiske kristne informanter i Accra. På den ene side er bøn for dem et vigtigt centripetalt middel til at kultivere en disciplineret selvopfattelse og dermed en måde, centrifugalt, at modvirke de kaotiske og problematiske socioøkonomiske og politiske tilstande i Accra på. På den anden side er de højlydte kendetegn ved karismatisk bøn, som den praktiseres, når den er mest intens og dermed åndeligt mest kraftfuldt - råbende tungetale, klappende hænder, stampende fødder, musikalsk støj - et udtryk for en kortvarig, grænsebrydende eller deterritorialiserende handling, som for mine informanter bidrager til deres oplevelse af uorden og manglende disciplin, som de mener eksisterer 
både inden for og uden for kirken. Vi kan med rette anskue denne bevægelse mellem to kontraster med det, som Deleuze og Guattari har kaldt bevægelsen fra „stribede“ steder (striated spaces) mod ,glatte“ steder (smooth spaces) (Deleuze \& Guattari 2015:557-58).

Deleuze og Guattari har argumenteret, at urbane miljøer ofte er kendetegnet ved to modsatrettede tendenser: På den ene side er der såkaldte „smooth“ eller ,glatte“ steder, som er kendetegnet ved et fravær af orden (moralsk, politisk, religiøs, økonomisk osv.). Disse er dynamiske, skabende og åbne for betydning. På den anden side er der de såkaldte „striated“ eller „stribede“ steder, som Deleuze og Guattari hævder er karakteriseret ved orden og stabilitet. Når den ghanesisk presse og Mensa Otabil beskriver Accras urbane miljø som oversvømmet (jf. figur 1), er det netop bevægelsen mod et mere „glat“ urbant miljø. Det er denne iboende spænding, som jeg argumenterer, der kommer til udtryk gennem bøn: den dynamiske, højlydte og grænseløse bevægelse, som de karismatiske kirker er kendte for, på den ene side, og det statiske, ordnede, disciplinerede tilhørsforhold og den vedvarende karismatisk tro på den anden side. Som etnografisk fænomen og praksis er det styrken ved bøn, at den ikke lader sig reducere til det ene eller andet, men derimod eksisterer i spændingsfeltet mellem disse to kontraster.

Når jeg her relaterer bønnens iboende spænding mellem grænseløs tro og stedsbundet tilhørsforhold ved hjælp af begreberne stribede og glatte steder, er det for at illustrere, at de to aspekter af den karismatiske ontologi ikke er gensidigt udelukkende, men derimod gensidigt påvirkende og eksisterer i et dynamisk samspil, som kommer til udtryk gennem bøn. Det er vigtigt, fordi tidligere antropologiske studier af karismatisk pinsekristendom som nævnt ovenfor har fokuseret på uforeneligheden mellem disse aspekter (Meyer 1998, 1999; van Dijk 2001a, 2001b; de Witte 2008; Robbins 2004a, 2004b, 2006). Kendetegnet for disse tidligere studier af karismatisk pinsekristendom er, at konverteringen til kristendom sker efter et brud med en spirituel fortid, der symbolsk kapper båndene til et åndelige slægtskab med forfædrene og samtidig kapper båndene til et territorielt tilhørsforhold til et givent sted. Disse studier kan dermed placeres inden for Hervieu-Légers religiøse modernitet som beskrevet ovenfor. I det omfang den religiøse modernitet placerer de karismatiske kristne i direkte opposition til andre kristne fællesskaber, hvis orientering er mod stabilisering af tilhørsforhold og kontinuitet (som Abokobi eksemplificerer), peger det etnografiske materiale, der er præsenteret og diskuteret i denne artikel, på behovet for en mere nuanceret forståelse af forholdet mellem den idealiserede grænseløse tro og det lokale tilhørsforhold. Som Premawardhana (2020) har argumenteret, har der blandt tidligere antropologiske studier af verdensreligioner såsom karismatisk kristendom været tendens til at fremstille disse religioner som fællesskaber, der skaber absolutte, 
homogene identiteter i kontrast til andre ligeledes homogene identiteter, hvilket er problematisk, fordi det overser kompleksiteten i hverdagens kontraster. I konteksten af HCI ses det, hvordan tvetydighed og kontraster præger hverdagen for de troende, som kommer til udtryk gennem bøn. Bøn er for flere medlemmer af HCI på den ene side en etisk og moraliserende kraft, der virker både centripetalt og centrifugalt. På den anden side er lyden af bøn for dem emblematisk for den manglende orden, som de mener præger bylivet i Accra og i stigende grad påvirker menigheden i HCI. Denne analytiske tilgang læner sig op ad blandt andre Girish Daswani, som i sit studie af ghanesiske pinsekristne i Ghana og England har bemærket, at der er behov for en analytisk tilgang, som fastholder alsidighed og kompleksitet i religiøs praksis og erfaring, hvis det skal afspejle den oplevede erfaring for de troende (Daswani 2015:205).

Det er ikke for at affeje de karismatiske ghaneseres optagethed af konvertering og det absolutte om end idealiserede brud med fortiden. Diskursen i kirker som HCI er ikke blot et ekko af den diskontinuitet, som Meyer, Robbins, van Dijk og flere har dokumenteret; den er nok snarere en forstærkning af budskabet om diskontinuitet. Bruddet med tidligere tider og identiteter var til stede i alle bønnemøder, jeg deltog i, hvad enten de foregik i Isaacs og Doreens stue, i HCI eller til større konferencer. Men det interessante her er, at det var så præsent, at det næsten blev trivielt. I livet som medlem af HCI vil de fleste deltage i bønnemøder og gudstjenester fire-fem gange om ugen, og hver gang blev medlemmerne opfordret til at kaste deres tidligere liv bort, ,at vende bordet“, „opleve en transformation“, „,kaste fortidens lænker“ med videre. Dertil kommer, at det ikke var sjældent for folk at blive genfødt gentagne gange. Flere af mine informanter var blevet genfødt fem, seks, syv gange. Snarere end et definitivt og uigenkaldeligt vendepunkt var omvendelse eller genfødsel i deres karismatiske tilværelse præget af en forventelig diskurs om det transformative i en sådan en grad, at det blev en forventelig og næsten triviel og dermed mindre betydelig del af hverdagen, som i stedet trådte i baggrunden for mere presserende bekymringer. For Isaac og Doreen som for lederne i HCI var behovet for mere vedholdende disciplin og permanent tilhørsforhold en uvant bekymring, som havde negative konsekvenser på deres trosfællesskab. Det konstante fokus på kortvarig transformation og flygtige opbrud i karismatisk praksis var for dem på flere måder blevet til problemet snarere end løsningen.

\section{Konklusion}

I denne artikel har jeg præsenteret etnografisk materiale, der peger på en fremherskende spænding mellem to kontraster, der kommer til udtryk gennem bøn: På 
den ene side fungerer bøn som en centripetal kraft, hvis formål er at kultivere et disciplineret kristent subjekt for derigennem at skabe en centrifugal kraft, hvis formål det er genoprette en social, moralsk og spirituel orden i Accra. På den anden side er den selvforstærkende effekt af utallige kirker, der alle forsøger at overdøve hinanden med centrifugal bøn og musik, blevet et tegn på den manglende orden og grænsedragning, der hersker i Accra. Denne manglende orden kobles sammen med et moralsk forfald og udisciplinerede troende, der i sidste ende afholder folk som Isaac og Doreen og kirker som HCI i at opnå resultaterne af deres tro. Lyden af bøn bliver altså både en kilde til social kritik og en måde, hvorpå den guddommelige kraft for en stund aktiveres i kampen mod dæmoniske magter, der forhindrer dem i at opnå resultater. Denne ambivalens, argumenterer jeg, er kendetegnende for oplevelsen af karismatisk kristen praksis og identitet for flere af medlemmerne i HCI i konteksten af Accras urbane udvikling. Og det er netop denne ambivalens eller spænding, som giver bøn dens særlige relevans blandt de ghanesiske kristne, som jeg arbejdede med. Bønnen er vigtig, ikke fordi den cementerer et absolut brud mellem individers fortid og nutid som genfødte kristne eller et brud mellem forskellige kristne retninger. Bønnen er vigtig på grund af dens iboende spænding, så medlemmer af HCI kontinuerligt og dynamisk kan positionere sig selv og deres tro i relation til bredere sociale forandringer, som påvirker deres liv og trossamfund.

For selvom de karismatiske kirker i Ghana til en vis grad siden begyndelsen har brugt de sociokulturelle og politiske omstændigheder i deres samfund som inspiration til deres teologiske budskab (Anaba 1993), er splittelsen mellem det ordnede og uordnede, mellem disciplin og højlydt bøn en fremherskende tendens, der blandt andet forårsages af udviklingen i det urbane, multireligiøse miljø i Accra, hvor HCI er ved at blive overdøvet af andre kirker. Problemet, fortalte mine informanter mig, kommer til udtryk i måden, hvorpå folk beder: den højlydte og intense karismatiske stil, som historisk har været de karismatiske kirkers kendetegn i Ghana. Men i og med at den guddommelige kraft bliver medieret gennem lyd, bliver troen lige så kortvarig og flygtig som lyden af bøn og sang. Derfor sker der i HCI et skift mod mere disciplinerede kristne subjekter. Dette ses blandt andet ved, at HCI nu forsøger at efterligne de historiske missionskirker, der på trods af deres forskellighed netop har kunnet bibeholde religiøs autoritet og territorielt tilhørsforhold gennem tiden, som det var tilfældet i Abokobi.

Eksemplerne fra denne artikel inviterer til en mere nuanceret forståelse af bønnens rolle blandt karismatiske kristne, hvor spændingen mellem orden og uorden ikke er gensidigt udelukkende, men forstærker hinanden på nye og dynamiske måder i relation til de sociokulturelle kontekster, som troen - og herunder bønnen - udfolder sig i. 


\section{Noter}

1. Eastwood Anaba er i Ghana kendt som en af stifterne af den karismatisk kristne bevægelse. Joel Osteen er en amerikansk karismatisk prædikant, der er kendt for sit budskab om, at troen medfører materiel velstand.

2. Begreberne „karismatisk“ og ,pinsekristen“ eller „,nykristen“ bruges virlkårligt til at beskrive den i grove træk samme kristne teologi. I denne artikel benævnes de karismatiske kristne, da det er deres egen beskrivelse af deres trosfællesskab.

3. Foruden engelsk er twi det mest talte sprog i det sydlige Ghana omkring Accra. Twi tales primært af folk med akanbaggrund, som samlet set er den største etniske gruppe i Ghana.

4. Bønnemøder, der varer k1. 22-05.

5. Karismatiske pinsekristne taler om at blive ,genfødt“ (born again), hvilket betyder, at man som voksen vedkender sig Jesus Kristus som sin personlige frelser og som oftest under ritualiserede omstændigheder i kirken.

\section{Litteratur}

Anaba, Joseph E.

1993 God's End-Time Militia. Winning the War Within and Without. Ghana: Design Solutions.

Bandak, Andreas

2014 Of Refrains and Rhythms in Contemporary Damascus. Current Anthropology 55(10):248-S261. https://doi.org/10.1086/678409.

Csordas, Thomas J.

1997 Language, Charisma and Creativity. The Ritual Life of a Religious Movement. Berkeley: University of California Press.

Daswani, Girish

2015 Looking Back, Moving Forward. Transformation and Ethical Practice in the Ghanaian Church of Pentecost. Toronto: University of Toronto Press.

de Witte, Marleen

2008 Accra's Sounds and Sacred Spaces. International Journal of Urban and Regional Research 32:690-709. https://doi.org /10.1111/j.1468-2427.2008.00805.x.

2011 Touched by the Spirit. Converting the Senses in a Ghanaian Charismatic Church. Ethnos 76(4):489-509. https://doi.org /10.1080/00141844.2011.620711.

Deleuze, Gilles \& Félix Guattari

2015 A Thousand Plateaus. Capitalism and Schizophrenia. London, UK: Bloomsbury Academic.

Hervieu-Léger, Danièle

2002 Space and Religion. New Approaches to Religious Spatiality in Modernity. International Journal of Urban and Regional Research 26(1):99-105. https: //doi.org/10.1111/1468-2427.00365.

Hirschkind, Charles 
Kaminski, Joseph S.

$2014 \quad$ Sound Barrage. Threshold to Asante Sacred Experience through Music.

International Review of the Aesthetics and Sociology of Music 45(2):345-71.

Lauterbach, Karen

2010 Becoming a Pastor. Youth and Social Aspirations in Ghana. Young 18(3):259-78.

https://doi.org/10.1177/110330881001800302.

Marshall, Ruth

2009 Political Spiritualities. The Pentecostal Revolution in Nigeria. Chicago: The University of Chicago Press.

Meyer, Birgit

1998 Make a Complete Break with the Past. Memory and Post-Colonial Modernity in Ghana. Journal of Religion in Africa 28(3):316-49. https://doi.org/10.1163/ $157006698 X 00044$.

1999 Translating the Devil. Religion and Modernity Among the Ewe in Ghana, International African Library. London: Edinburgh University Press.

2009 "There Is a Spirit in that Image". Mass-Produced Jesus Pictures and ProtestantPentecostal Animation in Ghana. Comparative Studies in Society and History 52(01):100-30. https://doi.org/10.1017/S001041750999034X.

2011 Mediation and Immediacy. Sensational Forms, Semiotic Ideologies and the Question of the Medium. Social Anthropology 19(1):23-39. https://doi.org/ 10.1111/j.1469-8676.2010.00137.x.

Oosterbaan, Martijn

2009 Sonic Supremacy. Sound, Space and Charisma in a Favela in Rio de Janeiro. Critique of Anthropology 29(1):81-104. https://doi.org/10.1177/ $0308275 X 08101028$.

Premawardhana, Devaka

2020 In Praise of Ambiguity. Everyday Christianity through the Lens of Existential Anthropology. Journal of World Christianity 10(1):39-43.

Reinhardt, Bruno

2014 Soaking in Tapes. The Haptic Voice of Global Pentecostal Pedagogy in Ghana. Journal of the Royal Anthropological Institute 20:315-36. https://doi.org/10.1111/ 1467-9655.12106.

Robbins, Joel

2004a Becoming Sinners. Christianity and Moral Torment in a Papua New Guinea Society. Berkeley: University of California Press.

2004b The Globalization of Pentecostal and Charismatic Christianity. Annual Review of Anthropology 33(1):117-43. https://doi.org/10.1146/annurev.anthro.32.061002.093 421.

2006 On Giving Ground. Globalization, Religion, and Territorial Detachment in A Papua New Guinea Society. In: M. Kahler \& B.F. Walter (eds): Territoriality and Conflict in an Era of Globalization. Pp. 62-84. Cambridge: Cambridge University Press.

van Dijk, Rijk

2001a Time and Transcultural Technologies of the Self in the Ghanaian Pentecostal Diaspora. In: A. Corten \& R. Marshall-Fratani (eds): Between Babel and Pentecost. Transnational Pentecostalism in Africa and Latin-America. Pp. 216-34. London: Hurst/Bloomington.

$2001 \mathrm{~b} \quad$ Contesting Silence. The Ban on Drumming and the Musical Politics of Pentecostalism in Ghana. Ghana Studies 4:31-64. 
Weber, Max

1991

The Protestant Sects and the Spirit of Capitalism. In: H.H. Gerth \& C. Wright Mills (eds): From Max Weber. Essays in Sociology. Pp. 302-22. London:

Routledge. 